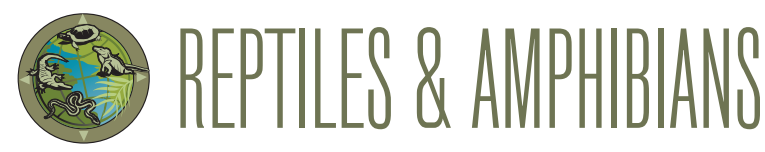

\title{
First Record of a "Mating Ball" in Bahamian Racers (Cubophis vudii) on Eleuthera, The Bahamas
}

\author{
Scott Johnson
}

Bahamas National Trust, P.O. Box N-4105, Nassau, Bahamas (sjohnson@bnt.bs; cubophisvudii@gmail.com)

$A^{t}$ t $1743 \mathrm{~h}$ on 29 March 2021, I became aware of a photograph of several snakes (Fig. 1) taken by James Lollo, a visitor to The Bahamas from the United States. In a Facebook post, he noted that he "stumbled across ... snakes (mating?)" in the area of Ten Bay Beach in central Eleuthera $\left(25^{\circ} 07^{\prime} 15.25^{\prime \prime} \mathrm{N}, 76^{\circ} 09^{\prime} 3.27^{\prime \prime} \mathrm{W}\right)$. The image showed at least five snakes coiled around each other. I confirmed the species to be Bahamian Racers, an endemic species in the family Dipsadidae. Several males appeared to be attempting to mate with a single female in a "mating ball."

Many species of snakes engage in complex reproductive behavior during the breeding season. Some species are known to engage in behavior during which several males compete with each other to mate with a female, forming what have been termed "mating balls" (e.g., Luiselli 1996; Shine et al. 2003; Friessen et al. 2014; Rivas 2020). However, such behavior has never been recorded in Bahamian Racers until now.

\section{Acknowledgments}

I thank Mr. James Lollo for providing photographs and videos of the Bahamian Racer mating ball and permission to use them for this publication.

\section{Literature Cited}

Friesen, C.R., R.T. Mason, S.J. Arnold, and S. Estes. 2013. Patterns of sperm use in two populations of Red-sided Garter Snake (Thamnophis sirtalis parietalis) with long-term female sperm storage. Canadian Journal of Zoology 92: 33-40. https://doi.org/10.1139/cjz-2013-0195.

Luiselli, L. 1996. Individual success in mating balls of the grass snake, Natrix natrix: Size is important. Journal of Zoology 239: 731-740. https://doi. org/10.1111/j.1469-7998.1996.tb05474.x.

Rivas, J.A. 2020. Anaconda: The Secret Life of the World's Largest Snake. Oxford University Press, New York, New York, USA.

Shine, R., T. Langkilde, and R.T. Mason. 2003. Confusion within 'mating balls' of garter snakes: does misdirected courtship impose selection on male tactics? Animal Behavior. 66: 1011-1017. https://doi.org/10.1006.anbe.2003.2301.



Fig. 1. A "mating ball” of Bahamian Racers (Cubophis vudii) at Ten Bay Beach on Eleuthera, The Bahamas. Photograph by James Lollo. 